\title{
Influence of changes in the scope of registered plant protection products on the level of herbicide contamination of waters in agricultural areas
}

\author{
Wpływ zmian w rejestrze środków ochrony roślin \\ na stopień zanieczyszczenia wód herbicydami na terenach rolniczych
}

\author{
Jerzy Sadowski, Mariusz Kucharski, Magdalena Dziągwa
}

\begin{abstract}
Summary
Surface and ground water monitoring was conducted on the areas where cereals, maize, rape and sugar beet were dominant crops. Three groups of active substances such as triazine, chloroacetamide and phenoxy acids derivatives were chosen to assess the influence of the changes in the registration of plant protection product on the frequency and level of herbicide residues in water. The residues of herbicide active substances were found both in surface and ground water. In 2002, the highest level of residues in surface water, were found to be phenoxy acids (2,4-D, MCPA, dicamba) and triazines (atrazine, simazine), amounted to $10^{-3} \mathrm{mg} / \mathrm{l}$. Chloroacetamides residues concentration was lower, and amounted to $10^{-5}-10^{-4} \mathrm{mg} / \mathrm{l}$. Whereas, in 2012 neither atrazine, nor simazine residues were detected in the surface water. However, in the ground water these substances are still present, but their concentration has significantly decreased $\left(10^{-5}-10^{-4} \mathrm{mg} / \mathrm{l}\right)$. It was also observed, that the concentration of fenoxy acids during the whole decade has not changed significantly in the ground water, and is maintained on a constant level of $10^{-4} \mathrm{mg} / \mathrm{l}$. Percentage of the samples in which herbicide residues were detected, varies between year 2002 till 2006 from 8.5 to $4.8 \%$, and now it is maintained on the same level. Noticeable decline in the herbicide residues concentrations in the ground and surface water is observed during the last five years, which is a result of the changes in the range of herbicides used.
\end{abstract}

Key words: herbicide; surface water; ground water; residues monitoring

\begin{abstract}
Streszczenie
Badania monitoringowe wód prowadzono na terenach rolniczych, gdzie dominowała uprawa zbóż, rzepaku i buraka cukrowego. Do oceny wpływu zmian w rejestrze środków na częstotliwość i poziom pozostałości herbicydów w wodzie zostały wybrane trzy grupy substancji czynnych: triazyny, pochodne chloroacetamidów i kwasów fenoksyalkanokarboksylowych. Pozostałości herbicydów wykryto zarówno w wodach powierzchniowych, jak też w wodach gruntowych. W roku 2002, w wodach powierzchniowych, najwyższe pozostałości rzędu $10^{-3} \mathrm{mg} / \mathrm{l}$ wykryto w przypadku 2,4-D, MCPA, dikamby, atrazyny i symazyny. Stężenie wykrytych pozostałości chloroacetamidów było niższe i wynosiło $10^{-5}-10^{-4} \mathrm{mg} / \mathrm{l}$. W roku 2012 nie wykryto pozostałości atrazyny i symazyny w wodach powierzchniowych. W wodach gruntowych substancje te są nadal obecne, a ich stężenie znacząco się obniża $\left(10^{-5}-10^{-4} \mathrm{mg} / \mathrm{l}\right) . \mathrm{W}$ całej ostatniej dekadzie stwierdzono, że stężenie pozostałości pochodnych kwasów fenoksyalkanokarboksylowych nie zmieniło się istotnie i w wodach gruntowych wynosiło $10^{-4} \mathrm{mg} / \mathrm{l}$. Odsetek próbek, w których wykryto pozostałości herbicydów zmienił się w latach 2002 do 2006 w zakresie od 8,5 do 4,8\% i do roku 2012 utrzymywał się na stałym poziomie. Zauważalny spadek stężenia pozostałości herbicydów w wodach powierzchniowych i gruntowych był obserwowany w ostatnim pięcioleciu, co jest wynikiem zmian w asortymencie stosowanych herbicydów.
\end{abstract}

Słowa kluczowe: herbicyd; wody powierzchniowe; wody gruntowe; monitoring pozostałości

Instytut Uprawy Nawożenia i Gleboznawstwa - Państwowy Instytut Badawczy

Zakład Herbologii i Technik Uprawy Roli

Orzechowa 61, 50-540 Wrocław

j.sadowski@iung.wroclaw.pl 


\section{Wstęp / Introduction}

Znaczącym elementem dzisiejszej technologii produkcji roślinnej jest stosowanie chemicznych środków ochrony roślin. Stosowanie preparatów chemicznych, obok niewątpliwych korzyści, obarczone jest potencjalnym ryzykiem powstawania szeregu zjawisk niekorzystnych w środowisku i niosących zagrożenia dla konsumentów.

Wody powierzchniowe i gruntowe na terenach rolniczych są narażone na zanieczyszczenie wynikające ze stosowania technologii w tym chemicznych środków ochrony roślin. Woda tych terenów może być również narzędziem transportu skażeń na tereny pozarolnicze. Niezbędne jest stałe monitorowanie potencjalnych zanieczyszczeń, które moga być ubocznym efektem stosowania agrochemikaliów.

W 1993 roku, zgodnie z Dyrektywą Unijną 91/414/ EWG, w Europie rozpoczął się proces przeglądu 1041 zarejestrowanych substancji czynnych. W efekcie tych działań, po 15 latach, 74\% substancji zostało wycofanych ze stosowania. W Polsce, w tym samym czasie dopuszczono do stosowania jedynie 31 nowych substancji czynnych (Matyjaszczyk 2011). Podstawą do oceny są między innymi badania dotyczące pozostałości i zachowania w środowisku substancji czynnych. Jednym z kierunków są badania nad przenikaniem herbicydów do środowiska wodnego.

W literaturze można znaleźć liczne przykłady przedsięwzięć badawczych dotyczących niekorzystnych zjawisk towarzyszących stosowaniu chemicznej ochrony roślin. Ze względu na koszty, nie są to nigdy działania na skalę kraju, a najczęściej odnoszą się do konkretnego regionu. Może to być wybrany ciek wodny, zlewnia rzeki lub obszar koncentracji wybranej uprawy (Frank i wsp. 1991; Albanis i wsp. 1998; Troiano i Garretson 1998; Quintana i wsp. 2001). Niezależnie od wyboru terenu, zawsze celem badań jest określenie skali i stopnia przedostawania się zanieczyszczeń środków ochrony roślin do wód na obszarze badań.

Szacując ryzyko zanieczyszczenia wód agrochemikaliami należy pamiętać, że znacznie bardziej niż wody gruntowe, na zanieczyszczenia narażone są wody otwarte (powierzchniowe). Herbicydy mogą się tam dostawać wskutek spłukiwania cząsteczek gleby ze skłonów, a przede wszystkim jako wynik nieprawidłowości w czasie wykonywania opryskiwania (znoszenie cieczy opryskowej, wylewanie resztek cieczy roboczej, mycie opryskiwaczy, itp.). Przenikanie agrochemikaliów do wód podziemnych powiązane jest między innymi $\mathrm{z}$ warunkami geologicznymi, konfiguracją terenu, wielkością i rozłożeniem w czasie opadów atmosferycznych. Wymienione czynniki sprawiają, że badania monitoringowe powinny obejmować dłuższy horyzont czasowy, co ma umożliwić określenie tendencji zmian w skali i stopniu skażenia wód powierzchniowych i podziemnych. Dłuższy okres obserwacji umożliwia również ocenę, jak zmiany w technologiach ochrony roślin, w tym zmiany asortymentu stosowanych substancji czynnych mogą wpływać na wielkość i częstotliwość występowania pozostałości środków ochrony roślin w wodach terenów rolniczych.

\section{Materiały i metody / Materials and methods}

Badania monitoringowe skażeń herbicydowych w warunkach polowych oparto o sieć stałych punktów pobierania próbek wody w terenie. Sieć rozpoczęto zakładać w roku 1983 na terenach rolniczych Dolnego Śląska w zlewniach rzek: Ślęzy, Oławy i Widawy (powiaty: wrocławski, oławski, strzeliński). Próbki wody pobrano z 45 punktów, z których 27 obejmuje płynące wody powierzchniowe (cieki śródpolne, rowy melioracyjne), a 18 wody studzienne (studnie o różnej głębokości). Próbki wody pobierano wiosną i jesienią (lata 2002-2012), około 3-6 tygodni po nominalnym okresie aplikacji herbicydów. Każdorazowo z określonego punktu pobierano około 5 litrów wody. Cztery litry wody dzielono na jednolitrowe porcje, a następnie ekstrahowano rozpuszczalnikiem organicznym (np. acetonitryl, dichlorometan, metanol). Otrzymane ekstrakty po odparowaniu do sucha przechowywano $\mathrm{w}$ zamrażarce $\mathrm{w}$ temperaturze $18^{\circ} \mathrm{C}$. Piąty litr stanowił rezerwę do ewentualnego powtórzenia analizy lub wykonania dodatkowych oznaczeń. Przechowywane w zamrażarce suche pozostałości poddawano sukcesywnie dalszej obróbce analitycznej. Pochodne kwasów fenoksyalkanokarboksylowych izolowano i oczyszczano metodą ekstrakcji do fazy stałej (SPE - solid phase extraction) na sorbencie oktadecylowym w następujący sposób: suchą pozostałość rozpuszczano w $5 \mathrm{ml}(3+2 \mathrm{ml}) \mathrm{H}_{2} \mathrm{O}$ zakwaszonej do $\mathrm{pH}=$ $2-2,5(18 \% \mathrm{HCl})$. Roztwór nanoszono na kolumnę SPE (Bakerbond Octadecyl $40 \mu \mathrm{m}$ ) przygotowaną w następujący sposób: 0,5 g sorbentu W kolumnie pojemności $3 \mathrm{ml}$. Aktywacja sorbentu kolejno: $5 \mathrm{ml}$ acetonu, $5 \mathrm{ml}$ metanolu, $5 \mathrm{ml}$ wody. Po naniesieniu próbki przemywano kolumnę $5 \mathrm{ml}$ wody destylowanej zakwaszonej do $\mathrm{pH}$ 2,5 $(18 \% \mathrm{HCl})$. Pozostałości wymywano dwoma porcjami metanolu $(2 \times 1 \mathrm{ml})$. Eluat osuszano bezwodnym siarczanem sodu i estryfikowano diazometanem. Pochodne chloroacetamidów i triazyn izolowano i oczyszczano metodą ekstrakcji do fazy stałej (SPE) na sorbencie oktadecylowym w następujący sposób: suchą pozostałość rozpuszczano w $5 \mathrm{ml}(3+2 \mathrm{ml}) \mathrm{H}_{2} \mathrm{O}$. Roztwór nanoszono na kolumnę SPE (Bakerbond Octadecyl $40 \mu \mathrm{m}$ ) przygotowaną $\mathrm{W}$ następujący sposób: 0,5 g sorbentu w kolumnie pojemności $3 \mathrm{ml}$. Aktywacja sorbentu kolejno: $3 \mathrm{ml}$ wody destylowanej, $3 \mathrm{ml}$ metanolu. Po naniesieniu próbki przemywano kolumnę $5 \mathrm{ml}$ wody destylowanej. Pozostałości wymywano dwoma porcjami acetonu $(2 \times 1 \mathrm{ml})$. Do finalnego oznaczenia pochodnych kwasów fenoksyalkanokarboksylowych i chloroacetamidów stosowano chromatografię gazową $\mathrm{z}$ zastosowaniem detektora wychwytu elektronów (EC - electron capture). Chromatografię prowadzono w następujących warunkach: chromatograf gazowy Varian 3800, kolumna Varian VF-5MS (długości $30 \mathrm{~m}$, średnica $0,25 \mathrm{~mm}$ ), program temperatury $120-200^{\circ} \mathrm{C} 10^{\circ} \mathrm{C} / \mathrm{min}$. Gaz nośny azot $1 \mathrm{ml} / \mathrm{min}$., detektor $\mathrm{EC}-300^{\circ} \mathrm{C}$. Weryfikację wyników budzących wątpliwość, np. wykrycie wyjątkowo ,dużych” pozostałości, dokonywano techniką GC/MS (gas chromatography/mass spectrometry) (Varian Saturn 2200). Pochodne triazyn oznaczano metodą chromatografii cieczowej (LC - liquid chromatography) $\mathrm{z}$ detekcją w UV (ultraviolet detection) 
(detektor spektrofotometryczny w zakresie bliskiego ultrafioletu). Chromatografię prowadzono w następujących warunkach: chromatograf cieczowy Shimadzu: LC-10AT (pompa), SPD-10A (detektor), CTO-10AS (termostat), SLC-10A (moduł sterujący), LCSolution (system sterowania i komputerowej rejestracji oraz obróbki sygnału). Kolumna LiChrosorb RP Select-B długości $250 \mathrm{~mm}$, średnica 4,6 mm. Faza ruchoma: acetonitryl:woda:metanol $(50: 40: 10 \mathrm{v} / \mathrm{v} / \mathrm{v})$, przepływ $0,2 \mathrm{ml} / \mathrm{min}$. Detektor UV $-240 \mathrm{~nm}$. Odzysk stosowanej metody wynosił $85-90 \%$ dla pochodnych kwasów fenoksyalkanokarboksylowych i 92-97\% dla pochodnych triazyn i chloroacetamidów. Granica oznaczalności w zależności od badanego związku leżała w przedziale 0,00002-0,00004 mg/l.

\section{Wyniki i dyskusja / Results and discussion}

Do oceny wpływu zmian w asortymencie stosowanych substancji czynnych na częstotliwość i poziom występowania pozostałości herbicydowych w wodach terenów rolniczych wybrano trzy grupy tych substancji. Pochodne triazyn, wśród których nastąpiły w ostatniej dekadzie największe ograniczenia w stosowaniu, a od roku 2007 zaprzestanie stosowania między innymi atrazyny i symazyny (2004/248/WE). Grupę pochodnych chloroacetamidów, w której w ostatnim dziesięcioleciu nastapiły częściowe ograniczenia stosowania. Jako grupę porównawczą wybrano pochodne kwasów fenoksyalkano- karboksylowych, których stosowanie nie uległo w ostatniej dekadzie większym zmianom.

Badania monitoringowe wód powierzchniowych i studziennych prowadzono na terenach, na których dominowała uprawa zbóż, rzepaku i buraka cukrowego. Ponadto, jak wynikało z przeprowadzonego wywiadu, na omawianych terenach stosowano dość intensywną, chemiczną ochronę upraw przed chwastami. Na tej podstawie wybrano kilkanaście substancji czynnych herbicydów, których stosowanie było najczęstsze. W tabeli 1. przedstawiono wyniki ilustrujące maksymalne pozostałości wybranych substancji czynnych wykryte na początku i na końcu okresu badań. Wyniki ilustrujące zmiany w częstotliwości wykrywania pozostałości w wodach powierzchniowych i gruntowych oraz trend zmian przedstawiono na rysunkach 1 . i 2 . W wodach powierzchniowych, jak i gruntowych, wykrywano pozostałości monitorowanych substancji czynnych herbicydów. W roku 2002, w wodach powierzchniowych, najwyższe pozostałości (rzędu $10^{-3} \mathrm{mg} / \mathrm{l}$ ), to pozostałości substancji $\mathrm{z}$ grupy pochodnych fenoksykwasów (2,4-D, MCPA, dikamba) i triazyn (atrazyna, symazyna). Pozostałości chloroacetamidów wykrywano w mniejszych ilościach rzędu $10^{-5}-10^{-4} \mathrm{mg} / \mathrm{l}$.

Na początku dekady lat 2002-2012, w próbkach wód powierzchniowych pobieranych wiosna, obecność pozostałości pochodnych triazynowych wykrywano w blisko $10 \%$ próbek. Były to głównie atrazyna i symazyna. Pozostałe związki wykrywano rzadziej (zwykle 1-3\% prób).

Tabela 1. Maksymalne pozostałości herbicydów wykryte w wodach powierzchniowych i gruntowych na terenach rolniczych Dolnego Śląska (2002-2012)

Table 1. Maximum residue of herbicides determined in surface and groundwater on agriculture terrain of Lower Silesia (2002-2012)

\begin{tabular}{|c|c|c|c|c|}
\hline \multirow{3}{*}{$\begin{array}{l}\text { Substancja czynna } \\
\text { Active substance }\end{array}$} & \multicolumn{4}{|c|}{$\begin{array}{c}\text { Pozostałości - Residue } \\
{[\mathrm{mg} / \mathrm{l}]}\end{array}$} \\
\hline & \multicolumn{2}{|c|}{$\begin{array}{l}\text { wody powierzchniowe } \\
\text { surface water }\end{array}$} & \multicolumn{2}{|c|}{$\begin{array}{l}\text { wody gruntowe } \\
\text { groundwater }\end{array}$} \\
\hline & 2002 & 2012 & 2002 & 2012 \\
\hline \multicolumn{5}{|c|}{ Triazyny - Triazines } \\
\hline Atrazine & 0,00128 & nw & 0,00048 & 0,00010 \\
\hline Simazine & 0,00104 & nw & 0,00036 & 0,00008 \\
\hline Cyanazine & 0,00012 & nw & 0,00006 & nw \\
\hline Metamitron & 0,00018 & 0,00012 & 0,00008 & 0,00012 \\
\hline \multicolumn{5}{|c|}{ Fenoksykwasy - Phenoxy acids } \\
\hline 2,4-D & 0,00136 & 0,00102 & 0,00034 & 0,00026 \\
\hline MCPA & 0,00220 & 0,00188 & 0,00052 & 0,00042 \\
\hline Dichlorprop & 0,00008 & nw & 0,00002 & nw \\
\hline Dicamba & 0,00048 & 0,00050 & 0,00014 & 0,00018 \\
\hline \multicolumn{5}{|c|}{ Chloroacetamidy - Chloroacetamide } \\
\hline Alachlor & 0,00016 & 0,00012 & nw & nw \\
\hline Acetochlor & 0,00024 & 0,00008 & 0,00008 & 0,00008 \\
\hline Dimetachlor & 0,00032 & 0,00012 & 0,00010 & nw \\
\hline Metazachlor & 0,00036 & 0,00008 & 0,00010 & 0,0008 \\
\hline
\end{tabular}

nw - pozostałości nie wykryto - residue did not detect $(\leq 0,00002 \mathrm{mg} / \mathrm{l})$ 
Większość (60-75\%) próbek z wynikami pozytywnymi zawierała pozostałości kilku substancji pochodnych triazynowych. W próbkach pobieranych jesienią pozostałości wykrywano znacznie rzadziej. Odsetek próbek z pozostałościami nie przekraczał 3\%. Dotyczy to zarówno pojedynczych związków, jak i pozostałości wielu substancji.

W wodach gruntowych (studziennych) częstotliwość wykrywania pochodnych triazynowych była nieco inna. Obecność pozostałości wykrywano w około 8\% próbek. Podobnie, jak w wodach powierzchniowych, były to głównie atrazyna i symazyna (blisko 90\% wszystkich pozytywnych wyników), pozostałości wielu substancji stwierdzono w blisko 70\% próbek, w których wykrywano pozostałości. Dane te odnoszą się do próbek pobieranych wiosną. W okresie jesiennym jedynie częstotliwość występowania atrazyny i symazyny nie ulegała większym zmianom. Natomiast pozostałe $\mathrm{z}$ pochodnych triazyn wykrywano sporadycznie (1-5\% wyników pozytywnych). Jesienią odsetek próbek z pozostałości wielu substancji był niewielki i nie przekraczał 3\%. Stopień zanieczyszczenia wód powierzchniowych i gruntowych herbicydami triazynowymi uległ wyraźnej zmianie po zaprzestaniu stosowania większości tych substancji w roku 2007. Od tego momentu obserwowany jest stały spadek obecności tych substancji w wodach terenów rolniczych. Jednak ze względu na znaczną trwałość większości pochodnych triazynowych, ich obecność w wodach malała w okresie pięciu ostatnich lat stopniowo. W roku 2012 nie wykryto w wodach powierzchniowych obecności atrazyny i symazyny. Natomiast w wodach gruntowych substancje te sa nadal obecne, ale ich stężenie uległo wyraźnie obniżeniu $\left(10^{-5}-10^{-4} \mathrm{mg} / \mathrm{l}\right)$.
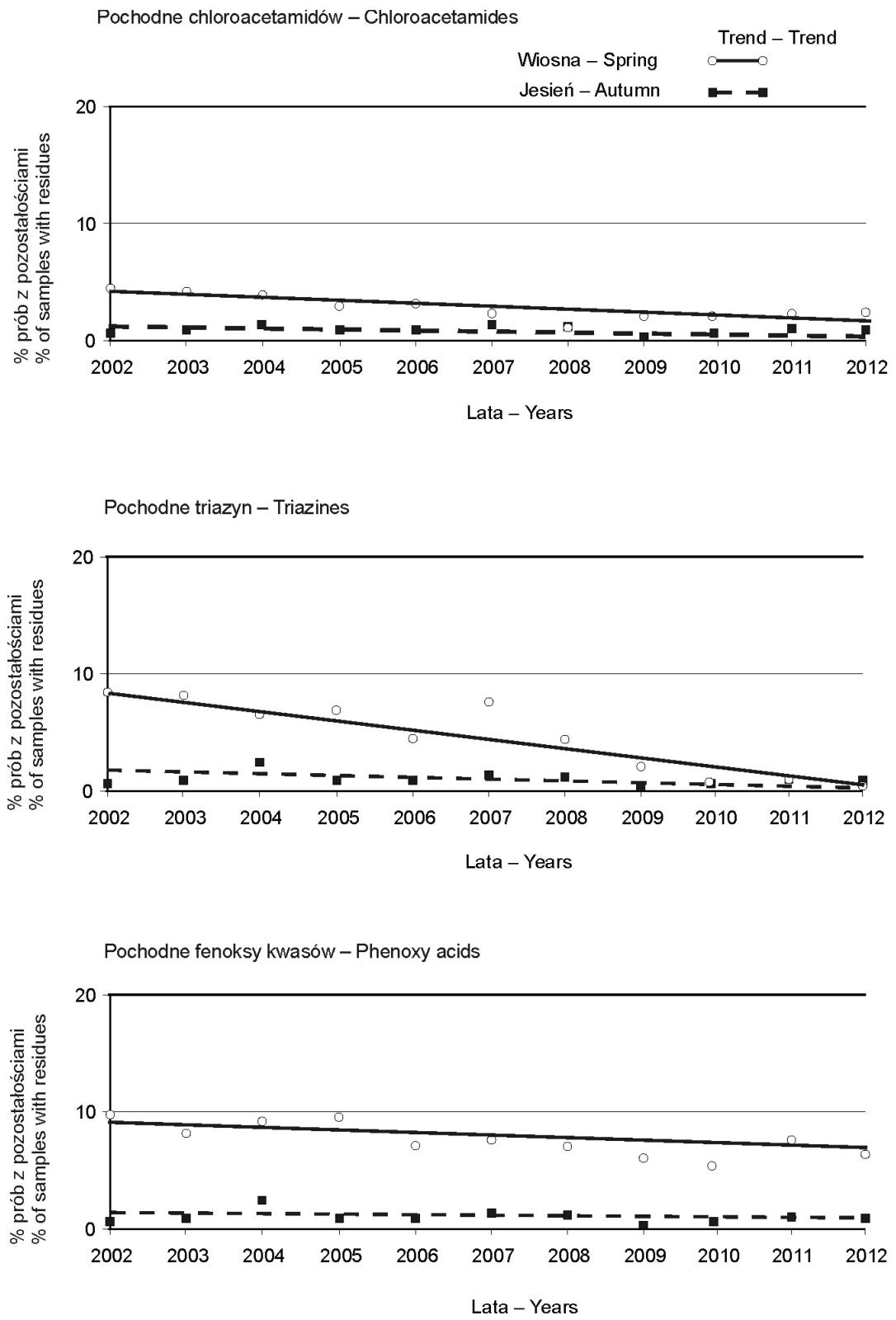

Rys. 1. Procentowy udział próbek z pozostałościami (wody powierzchniowe)

Fig. 1. Percentage of samples with residues (surface water) 

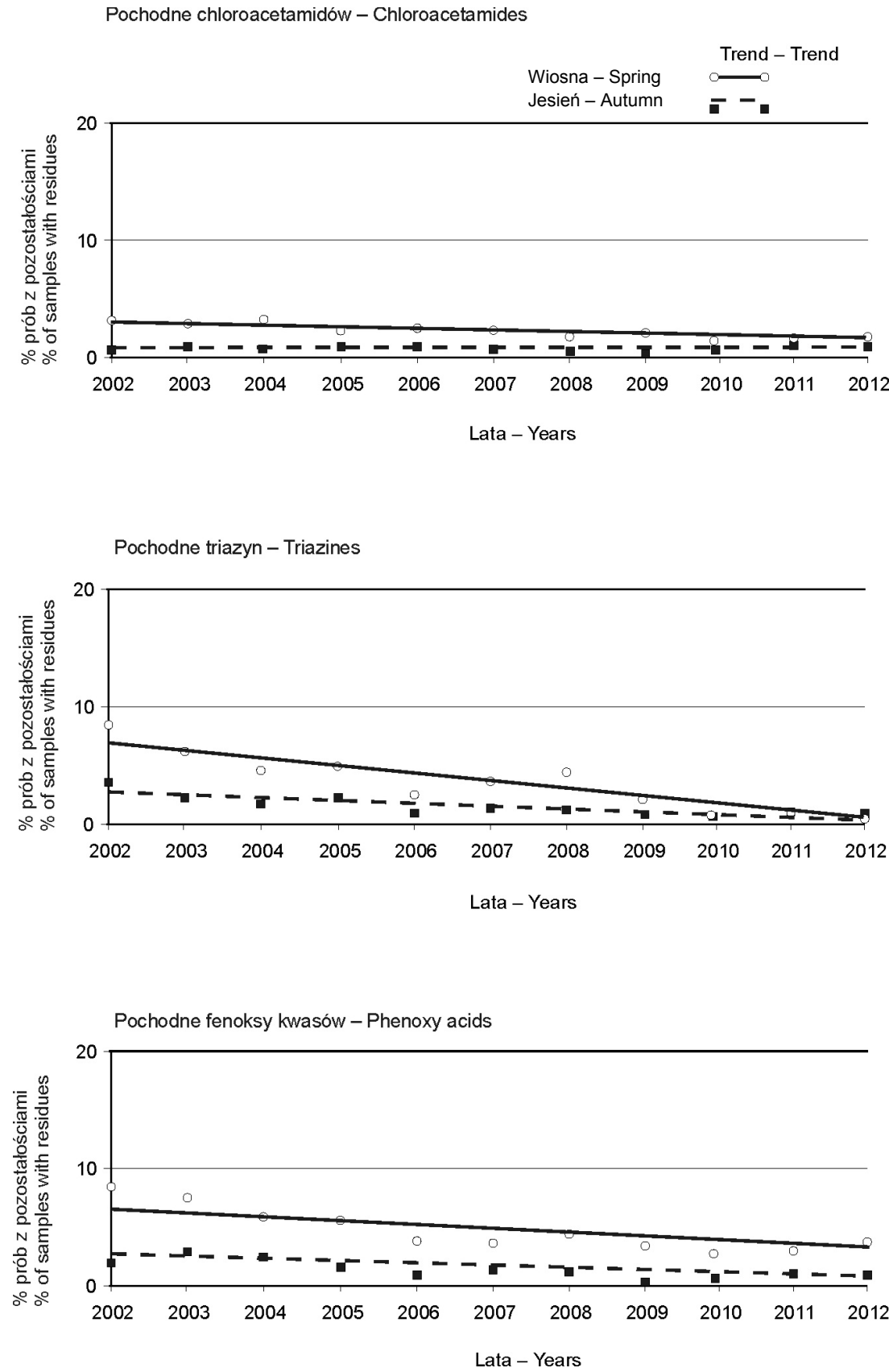

Rys. 2. Procentowy udział próbek z pozostałościami (wody gruntowe)

Fig. 2. Percentage of samples with residues (groundwater)

Obecność pochodnych chloroacetamidów w latach 2002-2012 ulega również stopniowej redukcji z 4\% w roku 2002, do blisko $2 \% \mathrm{w}$ roku 2012. Należy jednak zaznaczyć, że od roku 2007 odsetek wyników pozytywnych nie ulegał istotnym zmianom. Substancje wycofane, takie jak alachlor, nie są już w wodach gruntowych wykrywane, ale w wodach powierzchniowych sporadycznie odnotowywano obecność tego związku, pomimo oficjalnego zaprzestania jego stosowania. Herbicydy zawierające tą grupę pochodnych znajdujące się w zaleceniach są regularnie wykrywane głównie w wodach powierzchniowych. Odsetek próbek z tą grupą herbicydów wiosną w roku 2012 wyniósł około $2 \%$, a w wodach gruntowych nie przekroczył 1\%. Poziom pozostałości zawierał się w granicach $10^{-5}-10^{-4} \mathrm{mg} / \mathrm{l}$. Pozostałości chloroacetamidów wykrywano w wodach powierzchniowych i gruntowych głównie wiosną. W okresie jesiennym pozostałości tych substancji stwierdzano sporadycznie. Odsetek wyników pozytywnych nie przekraczał $1 \%$ badanych próbek.

Pochodne kwasów fenoksyalkanokarboksylowych w wodach powierzchniowych wykrywano na przestrzeni całej ostatniej dekady. Odsetek próbek, w których stwierdzono ich obecność w roku 2002 sięgał 10\%, a w roku 2012 niecałe $8 \%$. W wodach powierzchniowych wykrywano głównie 2,4-D, MCPA oraz dikambę, a spo- 
radycznie dichlorprop i MCPP. Maksymalny poziom stężeń w roku 2002 osiągał $10^{-3} \mathrm{mg} / \mathrm{l}$ i na przestrzeni całej dekady nie uległ zmianie. Podobnie, jak w przypadku wyżej wymienionych grup substancji czynnych, w wodach powierzchniowych dominowały pozostałości pochodnych kwasów fenoksyalkanokarboksylowych (84\% wszystkich wyników pozytywnych). W przypadku tej grupy substancji należy pamiętać, że zdecydowana większość preparatów chwastobójczych, w których zawarte są te związki to mieszaniny substancji czynnych. W wodach gruntowych maksymalne stężenia tej grupy związków na przestrzeni całej dekady nie uległo istotnym zmianom i utrzymują się one na poziomie $10^{-4} \mathrm{mg} / \mathrm{l}$. Odsetek próbek, w których wykrywano obecność tych związków zmieniał się w latach 2002-2006 z 8,5 do 4,8\% i do chwili obecnej utrzymuje się na tym poziomie.

$\mathrm{Na}$ obserwowane zmiany w występowaniu wszystkich trzech omawianych grup substancji czynnych składa się wiele przyczyn. Jako główne można wymienić zmiany pogodowe w ostatniej dekadzie, a szczególnie wielkość i rozkład w czasie opadów atmosferycznych (Sadowski i wsp. 2009), zmiany w technice ochrony roślin (DaSiva i wsp. 2003) oraz poszukiwanie sposobów obniżenia dawek środków ochrony roślin (Kucharski i wsp. 2010). To nie eliminuje jednak skażeń wód. Zmiany pogodowe i zmiany sposobu aplikacji herbicydów przyczyniają się głównie do zmian poziomu i częstotliwości występowania pozostałości. Redukcja dawek minimalizuje ryzyko przenikania pozostałości do wód gruntowych, ale nie eliminuje ich całkowicie. Zmiany w asortymencie stosowanych środków chwastobójczych wynikające z regulacji prawnych, a także wprowadzanie na rynek nowych formulacji i nowych substancji czynnych prowadzą do największych zmian w spektrum i wielkości zaniemczyszczeń wód pozostałościami. Jak wskazują uzyskane wyniki, nie są to przemiany gwałtowne. Jak widać $\mathrm{z}$ trendu zmian (rys. 1, 2), eliminacja pozostałości pochodnych triazynowych nie nastapiła zaraz po zaprzestaniu ich stosowania. Substancje, takie jak atrazyna i symazyna, przez wiele lat były podstawowymi i praktycznie jedynymi herbicydami stosowanymi w uprawie kukurydzy, ale też w sadownictwie. Porównując trendy występowania pozostałości wybranych grup substancji czynnych widać jednak wyraźnie, że dominującą przyczyną jest wycofanie z praktyki określonych związków. Substancje z grup pochodnych chloroacetamidów, wśród których nie wprowadzono tak rewolucyjnych zmian, jak w stosowaniu triazyn, występują $\mathrm{w}$ wodach $\mathrm{z}$ terenów rolniczych $\mathrm{w}$ mniejszym nasileniu, ale tendencja zniżkowa nie jest tak wyraźna, jak w przypadku triazyn. Pochodne kwasów fenoksyalkanokarboksylowych, w występowaniu których też odnotowuje się tendencję spadkową, stosowane są nadal jako dominujące $\mathrm{w}$ uprawach zbóż, ale obserwuje się znaczące uzupełnienie asortymentu o pochodne $\mathrm{z}$ grupy sulfonylomoczników. Ta ostatnia grupa substancji stosowana jest coraz powszechniej. Wzrasta też liczba publikacji, w tym również $\mathrm{z}$ badań występowania tych substancji w wodach powierzchniowych i gruntowych (Ouyang i wsp. 2009). Wyniki uzyskane w prezentowanych badaniach są również dowodem na to, jak zmiany $\mathrm{w}$ asortymencie środków ochrony roślin wpływają na stopień i poziom zanieczyszczeń wód pozostałościami agrochemikaliów.

\section{Wnioski / Conclusions}

1. W wodach powierzchniowych i gruntowych wykrywano obecność wszystkich monitorowanych substancji czynnych herbicydów.

2. Częstotliwość i skład pozostałości herbicydowych $\mathrm{w}$ wodach powierzchniowych i gruntowych odzwierciedla asortyment stosowanych na terenie badań środków chwastobójczych.

3. W wodach powierzchniowych częściej wykrywano pozostałości w okresie wiosennym (do 10\% prób), a $\mathrm{w}$ terminie jesiennym odsetek próbek $\mathrm{z}$ pozostałościami nie przekraczał 3\%.

4. W zdecydowanej większości wykrywano obecność kilku substancji równocześnie. Odnosi się to do blisko $70 \%$ przypadków wyników pozytywnych.

5. Od roku 2007 odnotowywany jest stały, znaczący spadek obecności związków triazynowych spowodowany wycofaniem tych substancji $\mathrm{z}$ użycia. Jest to dowód na istotny wpływ zmian asortymentu stosowanych substancji czynnych na poziom i częstotliwość występowania skażeń herbicydowych w wodach na terenach rolniczych.

6. Nasilenie ekstremalnych zjawisk pogodowych (zwłaszcza opadów atmosferycznych) powoduje wzrost wymywania pozostałości herbicydowych z gleby, ale równoczesne ich znaczne rozcieńczenie. Konsekwencją tego jest spadek stężenia wykrywanych zanieczyszczeń.

\section{Literatura / References}

Albanis T.A., Hela D.G., Sakellarides T.M., Konstantinou I.K. 1998. Monitoring of pesticide residues and their metabolites in surface and underground waters of Imathia (N. Greece) by means of solid phase extraction disks and gas chromatography. J. Chromatogr. A. 823: 59-71.

DaSilva A., Garretson C., Troiano J., Ritenour G., Krauter C. 2003. Relating simazine performance to irrigation management. Weed Technol. 17: 330-337.

Dyrektywa 91/414/EWG z dnia 15 lipca 1991 dotycząca wprowadzania do obrotu środków ochrony roślin. Dz. U. WE, L 230/1 z dn. 19.08.1991, 32 ss.

Frank R., Clegg B.S., Chapman N.D. 1991. Triazine and chloroacetamide herbicides in Sydenham River water and municipal drinking water, Dresden, Ontario, Canada, 1981-1987. Arch. Environ. Cont. Tox. 19 (3): 319-324. 
Kucharski M., Sadowski J., Domaradzki K. 2010. Ograniczanie dawek herbicydów - wpływ na zanieczyszczenie środowiska naturalnego. Zesz. Nauk. PTIE i PTG Rzeszów 13: 93-94.

Matyjaszczyk E. 2011. Rejestracja środków ochrony roślin w Polsce - historia, stan obecny i przyszłość. [Registration of plant protection products in Poland - the history, present state and future]. Prog. Plant Prot./Post. Ochr. Roślin 51 (1): 77-87.

Ouyang X., Zhang W., Xu J., Chang N., Pan C., Zhang J., Niu W. 2009. Determination of sulfonylurea herbicides in water using solidphase extraction followed by liquid chromatography with electrospray ion trap mass spectrometry. J. Anal. Chem. 64 (9): $959-964$.

Sadowski J., Kucharski M., Wujek B., Wysocki A. 2009. Multipozostałości herbicydów w wodach powierzchniowych i gruntowych na terenach rolniczych Dolnego Śląska. [Multiresidues of herbicides in surface and groundwater on cultivated terrain of Lower Silesia]. Prog. Plant Prot./Post. Ochr. Roślin 49 (4): 1923-1930.

Quintana J., Marti I., Ventura F. 2001. Monitoring of pesticides in drinking and related waters in NE Spain with a multiresidue SPGEGC-MS method including an estimation of the uncentainty of the analytical results. J. Chromatogr. A 938: 3-13.

Troiano J., Garretson C. 1998. Movement of simazine in runoff water from citrus orchard row middles as affected by mechanical incorporation. J. Environ. Quality 27: 488-494.

2004/248/WE Decyzja Komisji dotycząca niewłączenia atrazyny do załącznika I do dyrektywy Rady 91/414/EWG oraz cofnięcia zezwoleń na środki ochrony roślin zawierające tę substancję czynną. Dz. U., L 78 z dn. 16.03.2004, 53 ss. 